\title{
Premature vaginal delivery with breech presentation
}

\section{Hanne Christensen*}

Kildespringet 6, 2. tv., 6200 Aabenraa, Denmark

*Corresponding Author: Hanne Christensen, Kildespringet 6, 2. tv., 6200 Aabenraa, Denmark; Email: hanne.christensen@dadl.dk

Received: May 13, 2019; Accepted: May 22, 2019; Published: June 10, 2019;

\section{Short Note}

Only a few cases of extreme premature deliveries with breech presentation are described in the literature. An unavoidable delivery with a premature child before gestationweek 26-28 whether there is a caput or a breech presentation, there are reasons to prefer a vaginal delivery. You can 't change in worst case a very poor prognosis for the child in relation to psyko and somatic development. If you choose a cesarean section there are higher risks for the mother compared with vaginal delivery in mortality, aspiration, thromboembolic diseases, amnion emboli, higher risks for bleeding under the operation and infections subsequent. In the future you may see complications with adherences and infertility, following births often end with placenta accrete, placenta previa and ablatio placenta, rupture of uterus and higher frequencies of caesarean section.

Whether the mode of delivery is vaginal or cesarean section, there will be risk of traumatic complication in the delivery of the foetus. Higher risks after cesarean section are neonatal meconium aspiration, respiratoric distress, hypoxi, and in the childhood allergic and bowl diseases.

In the choose of delivery - vaginal or cesarean section-you are giving the mother a much better prognosis in a vaginal delivery and in any way you can't chance a poor prognosis to the child.

\section{References}

1. Ismail MA, Nagib N, Ismail T et al. Comparation of vaginal and cesarean section delivery of foetues in breech presentation. Perinat Med 1999; $27: 339-51$.

2. Herbst A, Kællen K. Influence of mode of delivery on neonatal mortality and morbidity in spontaneous premature delivery. Eur J Obstet Gynecol Reprod Biol 2007; 133: 25-9.

3. Markestad T, Kaaresen T, Rønnestad P et al. Early death, morbidity and need of treatment among extremely premature infants. Paediatrics 2005 ; 115 : $1289-98$. 